\title{
Expression of multidrug resistance-associated proteins in paediatric soft tissue sarcomas before and after chemotherapy
}

\author{
ARIANNA CITTI $^{1 *}$, RENATA BOLDRINI $^{1 *}$, ALESSANDRO INSERRA $^{2}$, ANNA ALISI $^{3}$, ROSANNA PESSOLANO $^{4}$, \\ ANGELA MASTRONUZZI ${ }^{4}$, ANGELICA ZIN ${ }^{5}$, LUIGI DE SIO ${ }^{4}$, ANGELO ROSOLEN ${ }^{5}$, \\ FRANCO LOCATELLI ${ }^{4,6}$ and DORIANA FRUCI ${ }^{4}$
}

${ }^{1}$ Pathology Department, ${ }^{2}$ Paediatric Surgery Department, ${ }^{3}$ Liver Unit, ${ }^{4}$ Paediatric Haematology/Oncology Department, IRCCS, Ospedale Pediatrico Bambino Gesù, Piazza S. Onofrio 4, I-00165 Rome; ${ }^{5}$ Pediatric Haematology/Oncology Department, University of Padova, Via Giustiniani 3, I-35128 Padova; ${ }^{6}$ University of Pavia, Corso Strada Nuova 65, I-27100 Pavia, Italy

Received November 22, 2011; Accepted January 10, 2012

DOI: $10.3892 /$ ijo.2012.1433

\begin{abstract}
Expression of multidrug resistance (MDR) proteins is thought to significantly contribute to the different biological/ clinical behaviour of soft tissue sarcomas (STS) of various histological types and clinicopathological stages, as they are responsible for active efflux of cytotoxic drugs from tumour cells. We investigated the expression of 3 MDR proteins, i.e., permeability glycoprotein 1 (P-gp), multidrug resistance-associated protein 1 (MRP1) and multidrug resistance 3 (MDR3), in 43 STS specimens from newly-diagnosed paediatric patients, 31 with rhabdomyosarcoma (RMS) and 12 with non-RMS STS. To assess the influence of chemotherapy on STS drug resistance, the number of MDR-associated protein-positive cells was determined in 15 patients on both primary lesions before chemotherapy and on residual tumour after chemotherapy. At least one of the MDR-associated proteins tested was detected in $84 \%$ of primary untreated STS specimens. In these specimens, MRP1 was detected in a high percentage $(70 \%)$ of the cases, followed by MDR3 in 58\% and P-gp in 44\%. Many specimens showed
\end{abstract}

Correspondence to: Dr Doriana Fruci, Immuno-Oncology Laboratory, Department of Paediatric Haematology/Oncology, IRCCS, Ospedale Pediatrico Bambino Gesù, Piazza S. Onofrio 4, I-00165 Rome, Italy

E-mail: doriana.fruci@opbg.net

${ }^{*}$ Contributed equally

Abbreviations: STS, soft tissue sarcomas; MDR, multidrug resistance; RMS, rhabdomyosarcoma; ARMS, alveolar rhabdomyosarcoma; ERMS, embryonal rhabdomyosarcoma; CF, congenital fibrosarcomas; MPNST, malignant peripheral nerve sheath tumours; SS, synovial sarcomas; P-gp, permeability-glycoprotein 1; MRP1, multidrug resistance-associated protein 1; MDR3, multidrug resistance 3

Key words: soft tissue sarcomas, multidrug resistance, multidrug resistance-associated proteins, chemotherapy resistance, paediatric tumours co-expression of two different MDR proteins. Interestingly, MDR3 was significantly associated with the presence of PAX3/ PAX7-FKHR transcripts in RMS $(\mathrm{p}<0.05)$. Moreover, expression of MRP1 and MDR3 was significantly more frequent in group III and IV tumours as compared with those of groups I and II ( $\mathrm{p}<0.01)$. After chemotherapy MRP1, MDR3 and, to a lesser extent, P-gp expression was found to be increased in most of the samples. The frequent expression of these MDR-associated proteins in primary tumour cells before chemotherapy and the increase of their levels after chemotherapy, suggest that these proteins play a pivotal role in conferring drug resistance and in producing therapy-induced differentiation on STS.

\section{Introduction}

Paediatric soft tissue sarcomas (STS) are a heterogeneous group of malignant tumours that originate from various non-epithelial tissues and account for $10 \%$ of all childhood tumours (1). Rhabdomyosarcoma (RMS) is the most common paediatric STS accounting for half of all STS cases (2), followed by congenital fibrosarcomas (CF), malignant peripheral nerve sheath tumours (MPNST) and synovial sarcomas (SS). These paediatric malignant tumours significantly differ in their biological behaviour and in their response to chemotherapy (3).

An important obstacle to be overcome for successful treatment of paediatric STS is represented by pre-existent or acquired resistance to both structurally and functionally different chemotherapeutic agents (4-8). Multidrug resistance (MDR) can be brought about through different mechanisms, including enhanced expression of cellular transporters, reduced drug uptake, modifications in detoxification processes, enhanced DNA repair processes, down-regulation of drug targets, changes in cell-cycle regulation and alterations in apoptotic pathways (9). Best studied is the overexpression of a family of membrane transporter proteins known as ATP-binding cassette (ABC) transporters $(10,11)$. These transporters decrease the intracellular concentration of cytotoxic compounds by actively pumping drugs out of cells. Permeability-glycoprotein 1 (P-gp) and MDR-associated protein 1 (MRP1) are the best characterized among $\mathrm{ABC}$ transporters in human $(7,11)$, and are known to be associated with MDR and to exhibit a similar resistance 
phenotype $(12,13)$. Another MDR-associated protein, named MDR3, is a close homologue of P-gp, which is known to be overexpressed in drug-resistant tumour cells $(14,15)$.

Expression of these MDR-associated proteins has been demonstrated in various primary untreated tumours (16-22). This suggests that MDR-associated genes may have a role in primary drug resistance observed during first-line chemotherapy. However, the role of MDR-associated proteins in the drug resistance acquired through chemotherapy and its correlation with the extension and evolution of the disease has not been fully investigated in paediatric STS.

Thus, the present work was carried out to examine the expression of the MDR-related proteins, namely P-gp, MRP1 and MDR3, before and after chemotherapy, in different primary paediatric STS (RMS, CF, MPNST and SS) by immunohistochemistry, and to correlate their expression levels with tumour malignancy and the presence of fusion gene transcripts.

\section{Patients and methods}

Patients and specimens. All tumour specimens were obtained from patients diagnosed from January 2001 to May 2011, at the 'Bambino Gesù' Children Hospital, Rome, Italy, after having obtained informed parental consent and approval from the Ethics Committee of the Institution. The surgical specimens were processed for routine histological examination by fixation in $4 \%$ phosphate-buffered formaldehyde for up to $18 \mathrm{~h}$ and subsequent embedding in paraffin (23). All specimens were examined by haematoxylin and eosin staining with additional immunohistochemical staining. The clinical features of the patients are detailed in Table I. Patients were classified according to the European Paediatric Soft Tissue Sarcoma Study Group (EpSSG) RMS-2005 for localized RMS, MMT-IV-89/91 or MMT-98 for metastatic RMS and EpSSG NRSTS 2005 for non-RMS. Tumours were graded after initial surgery according to the classification developed by the Intergroup Rhabdomyosarcoma Study (IRS)-IV system which includes the following 4 entities: group I, completely excised tumours; group II, grossly resected tumours with microscopic residual disease and/or completely excised positive regional lymph nodes; group III, gross residual disease after incomplete resection or biopsy; group IV, distant metastases at onset (24). Patients were treated according to the following protocols: AIEOP RMS96 for patients enrolled between 2001 and 2004 and EpSSG 2005 for patients enrolled since 2005.

Specimens of untreated (naïve-primary) STS were obtained from 43 paediatric patients, 19 male and 24 female, of which 31 with RMS (15 alveolar RMS, ARMS, and 16 embryonal RMS, ERMS), 6 with CF, 3 with MPNST and 3 with SS. Specimens of post-chemotherapy were available for 15 out of the 43 patients. The distribution of histological types roughly reflected the general incidence of STS (25). The mean age at diagnosis was 5.8 years (standard deviation, 6.6 years; range, 8 days to 203.3 months). Group distribution was as follows: 6 cases (13.9\%) for group I; 6 cases $(13.9 \%)$ for group II, 24 cases $(55.8 \%)$ for group III, and 7 cases $(16.3 \%)$ for group IV. Among group I tumours, there were two ERMS, three CF and 1 SS. Group II tumours included two ARMS, one ERMS, two MPNST and 1 SS. Group III tumours were 7 ARMS, 13 ERMS, 2 CF, 1 MPNST and 1 SS. Group IV tumours were $6 \mathrm{ARMS}$ and $1 \mathrm{CF}$.
$R T-P C R$ and real-time RT-PCR. Samples were tested for presence of specific fusion transcripts, i.e., PAX3/FKHR and PAX7/ FKHR for RMS, ETV6-NTRK3 for CF and SYT-SSX for SS by RT-PCR. The TRIzol reagent (Invitrogen, Milan, Italy) was used to extract total RNA from frozen samples. One microgram of total RNA from each specimen was reverse-transcribed by using the SuperScript II Reverse Transcriptase (Invitrogen) and random hexamers. PCR amplification was performed by using the BioTaq DNA polymerase (Bioline, London, UK) according to the manufacturer's instructions. PCR reaction mixture contained $1.5 \mathrm{mM} \mathrm{MgCl}_{2}, 0.2 \mu \mathrm{M}$ of each primer, $1 \mathrm{X}$ PCR buffer, $0.4 \mathrm{mM}$ of each dNTPs, $0.5 \mathrm{U}$ of Taq polymerase, and $1 \mu \mathrm{l}$ of the RT product in a final $20 \mu \mathrm{l}$ reaction volume. Primers and PCR conditions for MyoD1, PAX3-FKHR, PAX7-FKHR (RMS) (26), ETV6-NTRK3 (CF) (27) and SYT-SSX (SS) (28) were previously published. In each sample, $\beta 2$-microglobulin expression was concomitantly assessed as a control for presence of amplifiable RNA and for efficiency of reverse transcription. PCR reaction products were electrophoresed through $2 \%$ agarose gels, and their sizes were determined by comparative analysis with DNA Marker VI (Roche, Milan, Italy). Results were confirmed in at least 2 independent reactions for each assay.

The absolutely RNA FFPE kit (Stratagene, Santa Clara, CA) was used to extract total RNA from formalin-fixed paraffin-embedded samples according to the manufacturer's instructions. Briefly, three $10-\mathrm{mm}$ slices were deparaffinized with d-limonene, washed with ethanol 100, 90 and $70 \%$, and digested with proteinase- $\mathrm{K}$ at $55^{\circ} \mathrm{C}$ for 3-18 h. The lysate was passed through a filter cartridge and RNA was eluted in $30 \mathrm{ml}$ elution buffer (10 mM Tris-HCl, $\mathrm{pH}$ 7.5). One microgram of total RNA was reverse-transcribed to cDNA using SuperScript III Reverse Transcriptase (Invitrogen) and random hexamers. Quantitative RT-PCR for detection of MyoD1, PAX3-FKHR and PAX7-FKHR was performed on ABI PRISM 7000 (Applied Biosystems, Foster City, CA) by using Taq-Man technology. The ABL gene was used as endogenous control. The primers and probes used for PCR amplification were designed using Primer3 software and are presented in Table II. Amplification and detection were performed with the following profile: 40 cycles with $2 \min 50^{\circ} \mathrm{C} ; 10 \min 95^{\circ} \mathrm{C} ; 15 \sec 95^{\circ} \mathrm{C} ; 1 \min 60^{\circ} \mathrm{C}$. Similarly, RT-PCR analysis for CF and SS specimens was performed using primers and PCR conditions described above.

Antibodies. The following monoclonal antibodies (mAb) were used: mouse mAb JSB-1 and MRPm6, directed against P-gp (1:50 dilution) and MRP1 (1:20 dilution), respectively, purchased from Monosan (Uden, The Netherlands), and mouse mAb antiMDR3 (clone P3 II-26, 1:50 dilution) purchased from Millipore (Milan, Italy).

Immunohistochemical staining. Immunohistochemical staining was performed according to the following protocol. Consecutive sections of paraffin-embedded tissue blocks were cut at $3 \mu \mathrm{m}$. Deparaffinization and antigen retrieval were performed with PT-link (Dako, Milan, Italy) in Tris/EDTA (pH 9.0) (Dako) for $15 \mathrm{~min}$ at $98^{\circ} \mathrm{C}$. Sections were incubated with primary mAbs for $45 \mathrm{~min}$ at room temperature. Staining was detected using a biotinylated-secondary antibody (Dako) for $15 \mathrm{~min}$ at room temperature, followed by incubation with streptavidin alkaline phosphatase (Dako). Bound streptavidin was detected with Fast 
Table I. Clinical characteristics of patients.

\begin{tabular}{|c|c|c|c|c|c|}
\hline Characteristics & ARMS & ERMS & $\mathrm{CF}$ & MPNST & SS \\
\hline No. of patients $(n=43)$ & 15 & 16 & 6 & 3 & 3 \\
\hline \multicolumn{6}{|l|}{ Age (years) } \\
\hline$\leq 10$ & 10 & 7 & 5 & 0 & 2 \\
\hline$>10$ & 5 & 9 & 1 & 3 & 1 \\
\hline \multicolumn{6}{|l|}{ Gender } \\
\hline Male $(n=19)$ & 6 & 7 & 2 & 2 & 2 \\
\hline Female $(n=24)$ & 9 & 9 & 4 & 1 & 1 \\
\hline \multicolumn{6}{|l|}{ Tumour size $(\mathrm{cm})$} \\
\hline$<5$ & 7 & 5 & 4 & 0 & 2 \\
\hline$\geq 5$ & 8 & 11 & 2 & 3 & 1 \\
\hline \multicolumn{6}{|l|}{ Initial primary tumour site } \\
\hline Genitourinary & 3 & 11 & 0 & 0 & 0 \\
\hline Head and neck & 3 & 2 & 1 & 0 & 0 \\
\hline Orbit & 1 & 0 & 0 & 0 & 0 \\
\hline Extremity & 4 & 1 & 2 & 1 & 1 \\
\hline Other & 4 & 2 & 3 & 2 & 2 \\
\hline \multicolumn{6}{|l|}{ IRS group } \\
\hline $\mathrm{I}$ & 0 & 2 & 3 & 0 & 1 \\
\hline II & 2 & 1 & 0 & 2 & 1 \\
\hline III & 7 & 13 & 2 & 1 & 1 \\
\hline IV & 6 & 0 & 1 & 0 & 0 \\
\hline 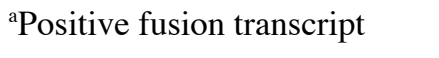 & 8 & 0 & 2 & - & 3 \\
\hline Negative fusion transcript & 7 & 16 & 0 & - & 0 \\
\hline Missing fusion transcript data & 0 & 0 & 4 & 3 & 0 \\
\hline
\end{tabular}

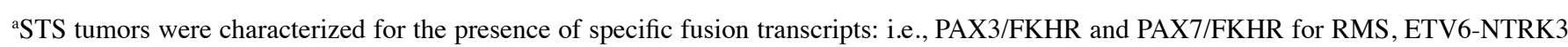
for CF and SYT-SSX for SS.

Table II. Real-time RT-PCR primers and probes.

\begin{tabular}{|c|c|c|c|}
\hline Transcript & & Sequence & Amplicon (bp) \\
\hline \multirow[t]{3}{*}{$\mathrm{ABL}$} & Forward & CAACACTGCTTCTGATGGCAA & 92 \\
\hline & Reverse & CGGCCACCGTTGAATGAT & \\
\hline & Probe & CAACACCCTGGCCGAGTTGGTTCAT FAM-TAMRA & \\
\hline \multirow[t]{3}{*}{ MyoD1 } & Forward & AGGCGCCTACTACAACGAGG & 76 \\
\hline & Reverse & CAGGCAGTCTAGGCTCGACAC & \\
\hline & Probe & GCCCAGCGAACCCAGGCCCGGGAA FAM-TAMRA & \\
\hline \multirow[t]{3}{*}{ PAX3-FKHR } & Forward & TGAACCCCACCATTGGCAAT & 67 \\
\hline & Reverse & CTGTGTAGGGACAGATTATGACGAA & \\
\hline & Probe & TGGCCTCTCACCTCAGAATTCAATTCGT FAM-TAMRA & \\
\hline \multirow[t]{3}{*}{ PAX7-FKHR } & Forward & GGTCAGCAACGGCCTGTCT & 80 \\
\hline & Reverse & CATTCTGCACACGAATGAACTTG & \\
\hline & Probe & CTCAGGAATTCAATTCGTCATAATCTGTCCCTACA FAM-TAMRA & \\
\hline
\end{tabular}



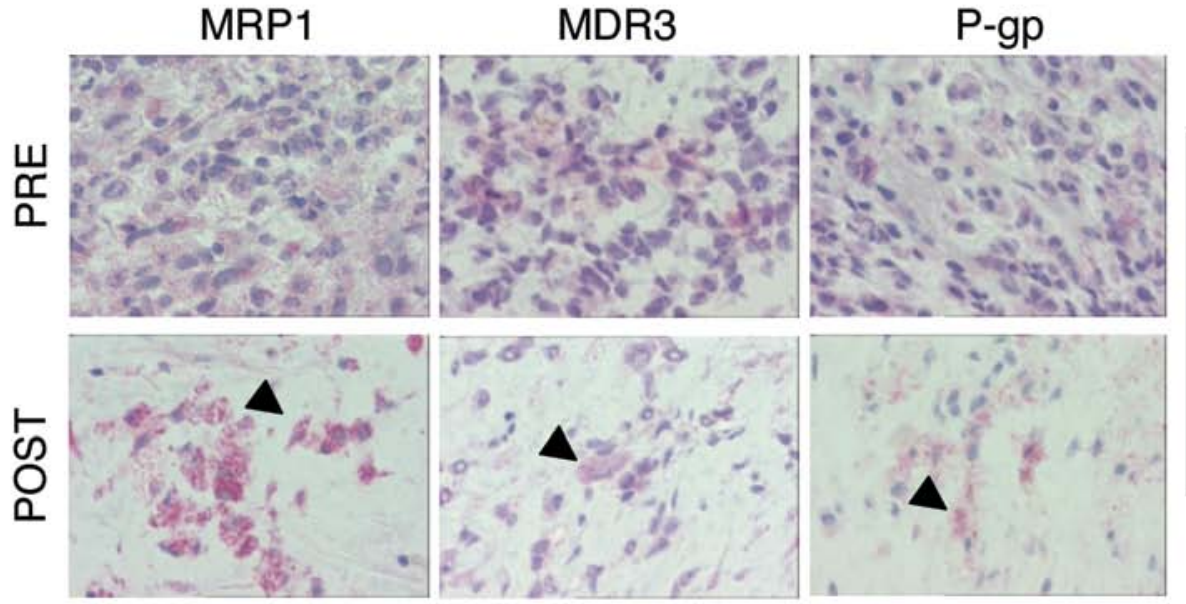

\section{RMS \#7}
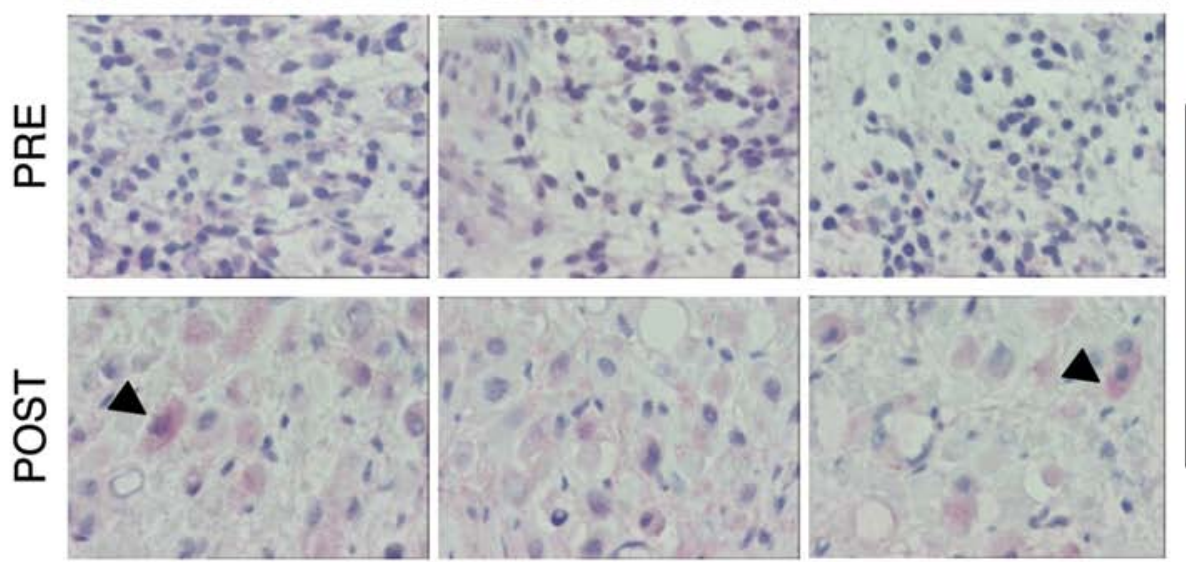

\section{RMS \#24}
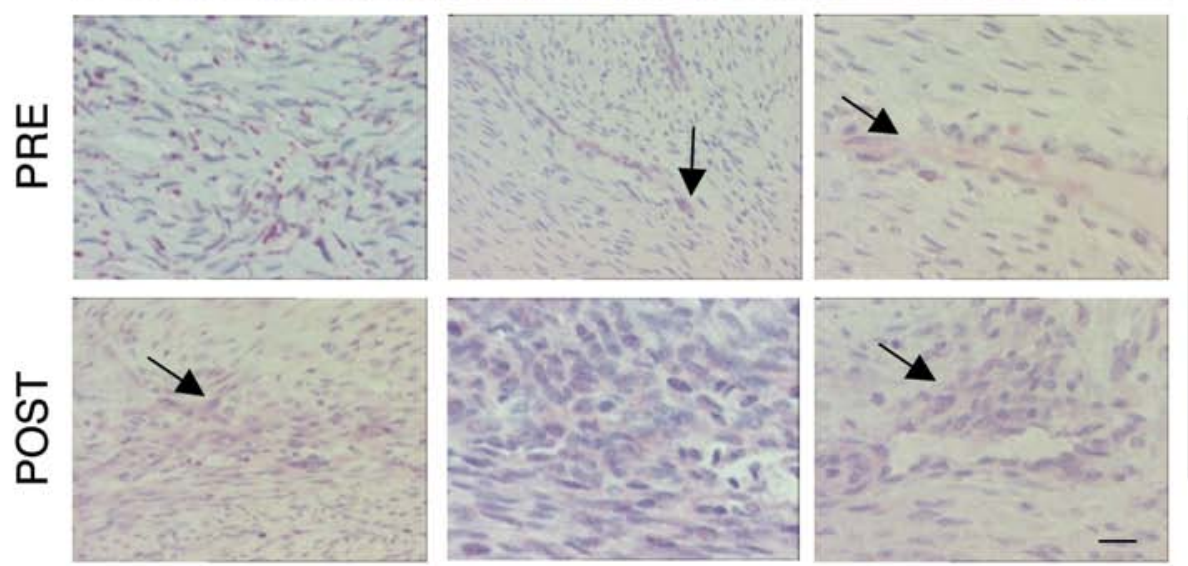

\section{MPNST \#40}

Figure 1. Expression of MDR-associated proteins in STS before and after chemotherapy. Immunohistochemical staining of MDR-associated proteins in RMS and non-RMS patients before (pre) and after (post) chemotherapy. Arrowheads indicate MDR-expressing tumour cells; arrows indicate MDR-expressing endothelium of small intratumoral vessels. Original magnification x40. Scale bars, $30 \mu \mathrm{m}$.

Red chromogene substrate (Dako) and levamisole in the reaction mixture for $10 \mathrm{~min}$ at room temperature. All samples were counterstained with haematoxylin. Sections of normal liver were used as positive controls for P-gp and MDR3, and kidney tissue for MRP1.

Scoring of immunohistological staining. The expression of MDR-associated proteins was independently assessed by two pathologists without any knowledge of the clinical data. The expression of P-gp, MRP1 and MDR3 was semi-quantitatively assessed by estimating the proportion of positively stained tumour cells. According to previous studies $(3,29)$, samples were considered negative when the staining was seen for $\leq 5 \%$ of tumour cells. Score 0 was assigned to this negative staining. Positive staining was categorised into: score 1 for $6-25 \%$ positive tumour cells, score 2 for $26-50 \%$ positive tumour cells, score 3 for $51-75 \%$ positive tumour cells and score 4 for $>75 \%$ positive tumour cells.

Statistical analyses. Statistical analysis was carried out with SPSS 12.0 for Windows software. Paired samples t-test was applied to compare the mean level of expression of the different MDR proteins within the same specimens. The Spearman's rank test was used to quantify the correlation between expres- 
sion of different MDR proteins. $\chi^{2}$ test was used to analyse the differences in MDR expression between histological types and clinicopathological groups. A two-tailed $\mathrm{p}<0.05$ was considered to be statistically significant.

\section{Results}

MDR-associated protein expression in untreated STS. In the 43 primary STS samples, all the $3 \mathrm{MDR}$-associated proteins (MDR proteins hereafter) tested, i.e., MRP1, MDR3 and P-gp, were detected either on cellular membranes or in the cytoplasm. In the cytoplasm, MDR protein staining showed a homogeneous pattern or a predominantly granular and partially homogeneous pattern, depending on the different histotypes (Fig. 1). Interestingly, positive MDR staining was detected in vascular endothelial cells.

The expression levels, graded by a score from 1 to 4 (see also Patients and methods), of the 3 MDR proteins tested are shown for samples from 43 pre-treated patients in Table IIIA. Expression of MRP1, MDR3 and P-gp was found in 30 cases (70\%), 25 cases (58\%) and 19 cases (44\%), respectively. In this group of STS samples, expression of MRP1 was significantly $(p<0.05)$ higher than that of MDR3 and P-gp. At least one of three MDR proteins was detected in 36 of the 43 cases investigated (84\%). Expression of all three proteins was found in 13 cases (30\%), whereas co-expression of MRP1 and MDR3, MDR3 and P-gp, and MRP1 and P-gp was found in 22 cases (51\%), 13 cases $(30 \%)$ and 16 cases $(37 \%)$, respectively. When the semi-quantitative scores (score 0 and score 1 to 4 ) were analysed, a significant correlation was found between MDR proteins. MRP1 expression correlated with that of MDR3 (Spearman's correlation coefficients 0.56; $\mathrm{p}<0.0001$ ) and P-gp (Spearman's correlation coefficients $0.40, \mathrm{p}<0.01$ ) as well as expression of MDR3 correlated with that of P-gp expression (Spearman's correlation coefficient $0.31 ; \mathrm{p}<0.05$ ).

MDR-associated protein expression in untreated STS of different histological types. Expression of MDR proteins in RMS (ARMS and ERMS) and non-RMS (CF, MPNST and SS) STS is illustrated as histogram for each of MRP1, MDR3 and P-gp in Fig. 2.

RMS samples, consisting of 15 ARMS and 16 ERMS, represent the largest group in this study. Among the 31 RMS samples, $22(71 \%)$ were positive for MRP1, 55\% were positive for MDR3 and $45 \%$ were positive for P-gp. P-gp expression did not differ between ARMS and ERMS. In contrast, MRP1 and MDR3 expression were different in the RMS histological subtypes: MRP1 and MDR3 were expressed in $12(80 \%)$ and in $11(73 \%)$ ARMS cases, respectively, whereas ERMS expressed MRP1 in 10 cases (63\%) and MDR3 in 6 cases (38\%), respectively. Thus, the frequency of expression of MDR3 was higher in ARMS than in ERMS $(\mathrm{p}<0.05)$.

Non-RMS samples, including 6 cases of CF, 3 cases of MPNST and 3 cases of SS, were characterized by high expression of both MRP1 and MDR3, the percentage of positive cases being $67 \%$ for both proteins. In all cases, the level of expression was scored 2 to 4 . P-gp staining was detected in $42 \%$ of the samples, in all cases with score 3-4.

MDR-associated protein expression in untreated STS in different clinicopathological groups. Expression of MDR proteins with
Table III.

A, MDR protein expression (score 1-4) in pre-treatment samples of STSs from all 43 patients tested.

\begin{tabular}{lrrr}
\hline Score & MRP1 & MDR3 & P-gp \\
\hline 0 & 13 & 18 & 24 \\
1 & 1 & 0 & 0 \\
2 & 4 & 2 & 3 \\
3 & 9 & 5 & 6 \\
4 & 16 & 18 & 10 \\
\hline
\end{tabular}

B, MDR protein expression (score 1-4) in pre- and posttreatment samples of STSs from 15 patients.

\begin{tabular}{|c|c|c|c|c|c|c|}
\hline \multirow[b]{2}{*}{ Score } & \multicolumn{2}{|c|}{ MRP1 } & \multicolumn{2}{|c|}{ MDR3 } & \multicolumn{2}{|c|}{ P-gp } \\
\hline & Pre & Post & Pre & Post & Pre & Post \\
\hline 0 & 7 & 3 & 12 & 6 & 9 & 6 \\
\hline 1 & 1 & 0 & 0 & 0 & 0 & 0 \\
\hline 2 & 1 & 0 & 0 & 1 & 2 & 2 \\
\hline 3 & 2 & 3 & 1 & 2 & 2 & 1 \\
\hline 4 & 4 & 9 & 2 & 6 & 2 & 6 \\
\hline
\end{tabular}

Score $0, \leq 5 \%$ positive tumour cells; score $1,6-25 \%$ positive tumour cells; score $2,26-50 \%$ positive tumour cells; score $3,51-75 \%$ positive tumour cells; score $4,>75 \%$ positive tumour cells. STS, soft tissue sarcomas. MRP1, multidrug resistance-associated protein 1; MDR3, multidrug resistance protein 3 , P-gp, P-glycoprotein. Percentage may not add up to $100 \%$ due to rounding of numbers.

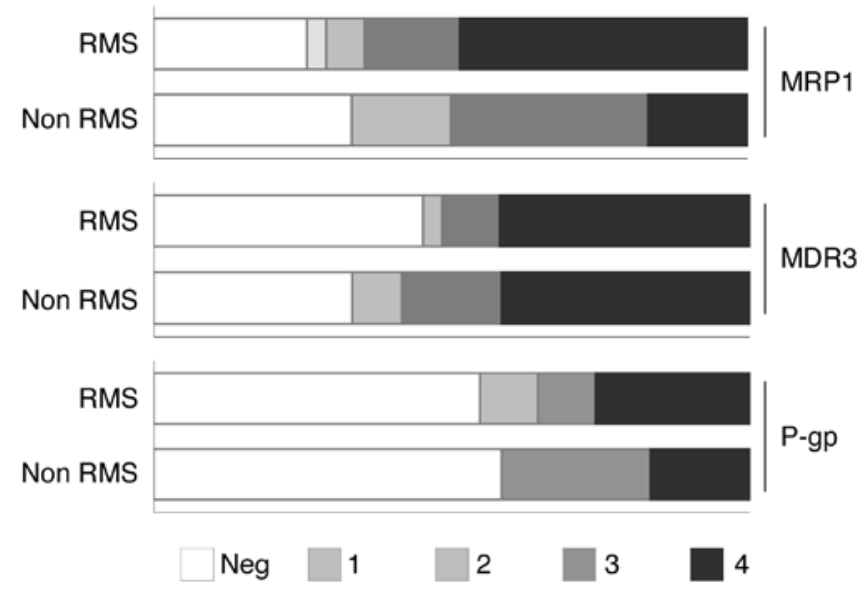

Figure 2. Expression of MDR-associated proteins per histological type. RMS group includes alveolar and embryonal RMS, whereas non-RMS group includes congenital fibrosarcoma, synovial sarcoma and malignant peripheral nerve sheath tumours.

respect to clinicopathological group is shown in Table IV. MRP1 and MDR3 expression was significantly higher in high-risk group III and IV tumours [23 cases $(74 \%)$ and 20 cases $(65 \%)$ 
Table IV. Expression of MDR proteins in STS patients according to their group.

\begin{tabular}{|c|c|c|c|c|c|c|c|c|c|c|c|c|}
\hline \multirow[b]{2}{*}{ Scorelgroup } & \multicolumn{4}{|c|}{ MRP1 } & \multicolumn{4}{|c|}{ MDR3 } & \multicolumn{4}{|c|}{ P-gp } \\
\hline & I & II & III & IV & I & II & III & IV & I & II & III & IV \\
\hline 0 & 2 & 3 & 7 & 1 & 2 & 5 & 10 & 1 & 1 & 3 & 16 & 4 \\
\hline 1 & 0 & 0 & 1 & 0 & 0 & 0 & 0 & 0 & 0 & 0 & 0 & 0 \\
\hline 2 & 1 & 1 & 1 & 1 & 1 & 0 & 1 & 0 & 0 & 1 & 2 & 0 \\
\hline 3 & 1 & 1 & 5 & 2 & 0 & 0 & 3 & 2 & 3 & 1 & 1 & 1 \\
\hline 4 & 2 & 1 & 10 & 3 & 3 & 1 & 10 & 4 & 2 & 1 & 5 & 2 \\
\hline
\end{tabular}

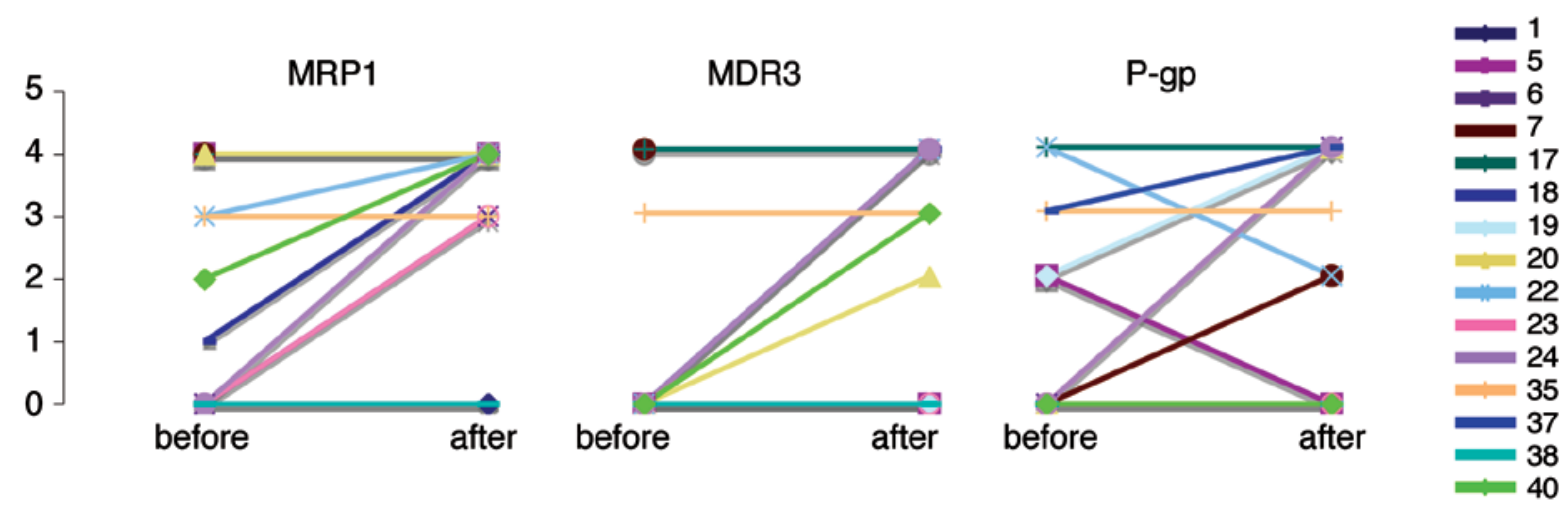

Figure 3. Expression of MDR-associated proteins in primary STS tumours and in residual tumour after chemotherapy. Pairwise comparison of MRP1, MDR3 and P-gp expression in primary STS tumours and in residual tumour after chemotherapy.

respectively] as compared with low-risk group I and II tumours [7 cases (58\%), 5 cases $(42 \%)$, respectively] ( $<<0.01)$. P-gp was found in 8 cases $(67 \%)$ of high-risk group III and IV tumours and 11 cases (35\%) of low-risk groups I and II, respectively.

MRP1 and MDR3 were more frequently co-expressed in high-risk groups III and IV with respect to low-risk groups I and II ( $\mathrm{p}=0.03)$, while MRP1 and P-gp or MDR3 and P-gp co-expression did not correlated with tumour group (not shown).

MDR-associated protein expression in untreated STS and their correlation with the presence of fusion transcripts. Most STS are characterized by the presence of chromosomal translocations, which results in the expression of different fusion transcripts, such as PAX3/PAX7-FKHR in RMS, ETV6-NTRK3 in CF and SYT-SSX in SS. All these translocations generate novel transcription factors that might inappropriately regulate the expression of unusual target genes or, possibly, have the ability to interact with other transcription factors to regulate expression of novel target genes. Thus, we investigated expression of MDR proteins in relation to the presence of PAX3/PAX7-FKHR fusion transcripts in RMS. The presence of PAX3/PAX7-FKHR fusion transcripts was significantly associated with MDR3 expression in RMS (Spearman's correlation coefficients 0.34, $\mathrm{p}<0.05$ ). No correlation between the presence of fusion transcripts and MRP1 or P-gp was detected.

MDR-associated protein expression in STS after treatment in comparison with that before treatment: a pairwise comparison. A comparative study on pre and post-therapy specimens was carried out in 11 RMS and 4 non-RMS, including 2 CF and 2 MPNST, with the aim of studying the effect of chemotherapy on MDR protein expression.

As shown in Table IIIB, the frequency of MDR protein expression in these 15 patients increased from 53 to $80 \%$ for MRP1 $(p<0.05)$, from 20 to $60 \%$ for MDR3 $(p<0.05)$, and from 40 to $60 \%$ for P-gp ( $<<0.05)$. In particular, treatment did not affect MRP1 expression in 8 samples, while induced an increase of its level in the remaining 7 samples. MDR3 expression was negative in 12 cases and strongly positive (score 3 or 4) in 3 cases before treatment. After chemotherapy, a marked increase of MDR3 expression, mostly score 4, was seen in 6 cases (Table IIIA and Fig. 3). P-gp was negative in 9 cases and positive in the remaining 6 cases (score 2-4) before treatment. P-gp expression remained unchanged in 7 cases, increased in 6 cases and decreased in 2 cases after chemotherapy. These data indicate that chemotherapeutic treatment is followed by an increased incidence and expression level of MDR proteins in a large fraction of STS regardless of histological types. Interestingly, MDR expression seems to be higher in betterdifferentiated tumour cells (Fig. 1).

\section{Discussion}

One of the most important causes of treatment failure in paediatric cancers is the acquisition of MDR (9). Various mechanisms are involved in clinical drug resistance, but best studied is overexpression of MDR proteins, which leads to decreased intracellular accumulation of cytotoxic drugs. 
MDR protein expression has been studied in various primary paediatric solid tumours $(3,17,18,20,30-35)$. De Cremoux et al investigated the clinical significance of mRNA expression level of MDR-associated genes in 29 advanced neuroblastoma samples and showed that P-gp and MRP1 mRNA overexpression was present in 74 and $30 \%$ of cases, respectively (31). Consistent with these findings, we found MDR proteins in a high percentage of primary STS (84\%). In particular, MRP1 expression was detected in the vast majority of primary STS (70\%), followed by MDR3 (58\%) and P-gp (44\%). Interestingly, positive MDR staining was detected also in vascular endothelial cells, this finding confirming the role of MDR proteins at this level.

Komdeur and colleagues assessed the expression of P-gp and MRP1 in 45 untreated RMS tumour specimens from both paediatric and adult patients and found most samples extensively positive for P-gp and MRP1 (80 and 56\% of cases, respectively) (20). We found that $60 \%$ of all STS displayed co-expression of at least two of the tested MDR proteins, suggesting the existence of common expressing-regulatory mechanisms.

The expression level of MDR proteins has been associated with the prognosis of the disease. Indeed, Norris et al demonstrated that a poor prognosis was correlated with high-level expression of MRP1 in primary neuroblastoma (18). Oda et al reported correlation between the MRP1 mRNA and degree of malignancy of STS (32). Nakaniski et al reported a correlation between tumour grade and P-gp expression when comparing high-grade tumours with low- and intermediate-grade STS (33). Accordingly, our data indicate that expression of MRP1 and MDR3 correlates with an advanced tumour malignancy and that these proteins are mainly co-expressed in the highrisk group as compared with low-risk group STS (not shown).

Resistance to chemotherapy may be due to protein-mediated MDR mechanisms already present in tumour cells before treatment, but it is also possible that repeated courses of chemotherapy modulate the expression of MDR proteins reducing treatment efficacy. Oue et al reported an increase of P-gp and MRP1 expression after chemotherapy in various paediatric tumours (36). On the basis of these already available data, we analyzed the expression of MDR proteins after chemotherapy. Our results demonstrate that expression of MDR proteins was either induced or significantly increased after chemotherapy in many tumour samples (Fig. 3).

Our own data, as well as previously reported studies, support the hypothesis that MDR proteins play a role in the clinical/ biological behaviour of paediatric sarcomas, both RMS and non-RMS, which are often characterized by poor response to therapy. The expression levels of MDR proteins both at diagnosis and during the course of chemotherapy treatment could represent important information to predict patient's prognosis. In fact, treated tumours that have acquired high levels of MDR proteins could relapse on and become resistant to the same or other drugs sharing similar mechanisms of resistance.

Two possible mechanisms may contribute to the increase in the expression of MDR proteins after chemotherapy: the clonal selection of MDR protein-expressing tumour cells and up-regulation of MDR proteins. In some cases, residual tumour cells showed a marked expression of MDR proteins after chemotherapy (Figs. 1 and 3). These results may indicate that chemosensitive tumour cells died, and only the residual tumour cells that express MDR proteins are clonally selected after chemotherapy. It is plausible that other mechanisms may contribute to the increased expression of MDR-associated genes after chemotherapy. Norris et al demonstrated a strong association between $\mathrm{N}$-myc and MRP1 expression in vivo and in a murine neuroblastoma model (18). Loss of p53 protein function, frequently found in sarcomas, has been hypothesized to contribute to up-regulation of the MRP1 gene (37). Cocker et al demonstrated that overexpression of MDM2, a negative regulator of the p53 tumour suppressor, results in an increased expression of MDR1 gene in RMS (38). However, it is also possible that chromosomal aberrations typical of certain STS variants could affect MDR expression. In this respect, we found a significant correlation between the presence of PAX3/PAX7-FKHR fusion transcript and MDR3 expression in RMS. This finding may indicate that a hybrid gene associated with tumour development can up-regulate the expression of MDR-associated genes, thereby increasing the malignant potential of the tumour.

Although the sample analyzed in this study is small and heterogeneous, our data indicate that the expression of MRP1, MDR3 and P-gp varies between different clinicopathological groups of STS, and it is conceivable that this might contribute to the differences observed in the response to chemotherapy of patients with STS. Our findings suggest that protein-mediated MDR in paediatric STS is a complex phenomenon that deserves further investigation in order to better understand how the expression of MDR proteins might predict tumour response to chemotherapeutic agents and, consequently the prognosis of the disease. Furthermore, approaches aimed at overcoming drug resistance of tumour cells through down-regulation of MDR proteins with small interfering RNA and pro-inflammatory cytokines $(39,40)$ could be explored in the future and lead to the development of novel treatment strategies of paediatric STS.

\section{Acknowledgements}

This work was supported by the IG grant AIRC (Associazione Italiana per la Ricerca sul Cancro) to D.F. and partly supported by the special project 5x1000 from AIRC to F.L.

\section{References}

1. Jain S, Xu R, Prieto VG and Lee P: Molecular classification of soft tissue sarcomas and its clinical applications. Int J Clin Exp Pathol 3: 416-428, 2010

2. Huh WW and Skapek SX: Childhood rhabdomyosarcoma: new insight on biology and treatment. Curr Oncol Rep 12: 402-410, 2010.

3. Klunder JW, Komdeur R, van Der Graaf WT, et al: Expression of multidrug resistance-associated proteins in rhabdomyosarcomas before and after chemotherapy: the relationship between lung resistance-related protein (LRP) and differentiation. Hum Pathol 34: $150-155,2003$.

4. Colvin OM: Drug resistance in the treatment of sarcomas. Semin Oncol 24: 580-591, 1997.

5. Gerlach JH, Bell DR, Karakousis C, et al: P-glycoprotein in human sarcoma: evidence for multidrug resistance. J Clin Oncol 5: 1452-1460, 1987.

6. Robert J: Multidrug resistance in oncology: diagnostic and therapeutic approaches. Eur J Clin Invest 29: 536-545, 1999.

7. Yoshikawa M, Ito A, Ishikawa T and Ikegami Y: [Drug resistance mediated by ABC transporters]. Gan To Kagaku Ryoho 31: 1-6, 2004.

8. Melguizo C, Prados J, Rama AR, et al: Multidrug resistance and rhabdomyosarcoma (Review). Oncol Rep 26: 755-761, 2011. 
9. Baguley BC: Multiple drug resistance mechanisms in cancer. Mol Biotechnol 46: 308-316, 2010.

10. Higgins $\mathrm{CF}$ : $\mathrm{ABC}$ transporters: from microorganisms to man. Annu Rev Cell Biol 8: 67-113, 1992.

11. Leonard GD, Fojo T and Bates SE: The role of ABC transporters in clinical practice. Oncologist 8: 411-424, 2003.

12. Gottesman MM, Pastan I and Ambudkar SV: P-glycoprotein and multidrug resistance. Curr Opin Genet Dev 6: 610-617, 1996.

13. Cole SP and Deeley RG: Multidrug resistance mediated by the ATP-binding cassette transporter protein MRP. Bioessays 20 931-940, 1998.

14. Nooter K, Sonneveld P, Janssen A, et al: Expression of the mdr3 gene in prolymphocytic leukemia: association with cyclosporinA-induced increase in drug accumulation. Int J Cancer 45 : 626-631, 1990

15. Herweijer H, Sonneveld P, Baas F and Nooter K: Expression of mdrl and mdr3 multidrug-resistance genes in human acute and chronic leukemias and association with stimulation of drug accumulation by cyclosporine. J Natl Cancer Inst 82: 1133-1140, 1990

16. Norris MD, Burkhart CA, Marshall GM, Weiss WA and Haber M: Expression of N-myc and MRP genes and their relationship to N-myc gene dosage and tumor formation in a murine neuroblastoma model. Med Pediatr Oncol 35: 585-589, 2000

17. Shapiro DN, Sublett JE, Li B, Downing JR and Naeve CW Fusion of PAX3 to a member of the forkhead family of transcription factors in human alveolar rhabdomyosarcoma. Cancer Res 53: 5108-5112, 1993.

18. Norris MD, Bordow SB, Marshall GM, Haber PS, Cohn SL and Haber M: Expression of the gene for multidrug-resistanceassociated protein and outcome in patients with neuroblastoma N Engl J Med 334: 231-238, 1996.

19. Warmann SW, Heitmann H, Teichmann B, et al: Effects of P-glycoprotein modulation on the chemotherapy of xenotransplanted human hepatoblastoma. Pediatr Hematol Oncol 22: 373-386, 2005

20. Komdeur R, Klunder J, van der Graaf WT, et al: Multidrug resistance proteins in rhabdomyosarcomas: comparison between children and adults. Cancer 97: 1999-2005, 2003.

21. Sola JE, Wojno KJ, Dooley W and Colombani PM: P-glycoprotein status of favorable-histology Wilms' tumor predicts treatmen outcome. J Pediatr Surg 29: 1080-1084, 1994.

22. Komdeur R, Plaat BE, van der Graaf WT, et al: Expression of multidrug resistance proteins, P-gp, MRP1 and LRP, in soft tissue sarcomas analysed according to their histological type and grade. Eur J Cancer 39: 909-916, 2003.

23. Flens MJ, Zaman GJ, van der Valk P, et al: Tissue distribution of the multidrug resistance protein. Am J Pathol 148: 1237-1247, 1996.

24. Crist WM, Anderson JR, Meza JL, et al: Intergroup rhabdomyosarcoma study-IV: results for patients with nonmetastatic disease. J Clin Oncol 19: 3091-3102, 2001.

25. Orbach D, Rey A, Oberlin O, et al: Soft tissue sarcoma or malignant mesenchymal tumors in the first year of life: experience of the International Society of Pediatric Oncology (SIOP) Malignant Mesenchymal Tumor Committee. J Clin Oncol 23: 4363-4371, 2005.
26. Sartori F, Alaggio R, Zanazzo G, et al: Results of a prospective minimal disseminated disease study in human rhabdomyosarcoma using three different molecular markers. Cancer 106: 1766-1775, 2006.

27. Argani P, Fritsch M, Kadkol SS, Schuster A, Beckwith JB and Perlman EJ: Detection of the ETV6-NTRK3 chimeric RNA of infantile fibrosarcoma/cellular congenital mesoblastic nephroma in paraffin-embedded tissue: application to challenging pediatric renal stromal tumors. Mod Pathol 13: 29-36, 2000.

28. Nilsson G, Skytting B, Xie Y, et al: The SYT-SSX1 variant of synovial sarcoma is associated with a high rate of tumor cell proliferation and poor clinical outcome. Cancer Res 59: 3180-3184, 1999.

29. Camassei FD, Ferlini C, Jenkner A, et al: Nephroblastoma. DNA characteristics and their modifications induced by prenephrectomy chemotherapy: a cytofluorimetric study. Pediatr Pathol Mol Med 21: 15-23, 2002.

30. Chan HS, Thorner PS, Haddad G and Ling V: Immunohistochemical detection of P-glycoprotein: prognostic correlation in soft tissue sarcoma of childhood. J Clin Oncol 8: 689-704, 1990.

31. De Cremoux P, Jourdan-Da-Silva N, Couturier J, et al: Role of chemotherapy resistance genes in outcome of neuroblastoma. Pediatr Blood Cancer 48: 311-317, 2007.

32. Oda Y, Schneider-Stock R, Rys J, Gruchala A, Niezabitowski A and Roessner A: Reverse transcriptase-polymerase chain reaction amplification of MDR1 gene expression in adult soft tissue sarcomas. Diagn Mol Pathol 5: 98-106, 1996.

33. Nakanishi H, Myoui A, Ochi T and Aozasa K: P-glycoprotein expression in soft-tissue sarcomas. J Cancer Res Clin Oncol 123: 352-356, 1997.

34. Kuttesch JF, Parham DM, Luo X, et al: P-glycoprotein expression at diagnosis may not be a primary mechanism of therapeutic failure in childhood rhabdomyosarcoma. J Clin Oncol 14: 886-900, 1996

35. Gallego S, Llort A, Parareda A and Sanchez De Toledo J: Expression of multidrug resistance- 1 and multidrug resistanceassociated protein genes in pediatric rhabdomyosarcoma. Oncol Rep 11: 179-183, 2004

36. Oue T, Yoneda A, Uehara S, Yamanaka H and Fukuzawa M: Increased expression of multidrug resistance-associated genes after chemotherapy in pediatric solid malignancies. J Pediatr Surg 44: 377-380, 2009.

37. Wang Q and Beck WT: Transcriptional suppression of multidrug resistance-associated protein (MRP) gene expression by wild-type p53. Cancer Res 58: 5762-5769, 1998 .

38. Cocker HA, Hobbs SM, Tiffin N, Pritchard-Jones K, Pinkerton CR and Kelland LR: High levels of the MDM2 oncogene in paediatric rhabdomyosarcoma cell lines may confer multidrug resistance. $\mathrm{Br}$ J Cancer 85: 1746-1752, 2001

39. Izquierdo M: Short interfering RNAs as a tool for cancer gene therapy. Cancer Gene Ther 12: 217-227, 2005.

40. Ho EA and Piquette-Miller M: Regulation of multidrug resistance by pro-inflammatory cytokines. Curr Cancer Drug Targets 6: $295-311,2006$ 